\title{
A New Efficient Binarization Method for MRI of Brain Image
}

\author{
Sudipta Roy, Ayan Dey, Kingshuk Chatterjee, Prof. Samir K. Bandyopadhyay \\ Department of Computer Science and Engineering, University of Calcutta, \\ 92 A.P.C. Road, Kolkata-700009, India. \\ sudiptaroy01@yahoo.com, deyayan9@gmail.com, \\ kingshukchaterjee@gmail.com, skbl@vsnl.com
}

\begin{abstract}
This paper proposes a new image binarization method that uses a simple standard deviation approach and gives us very good results for MRI of brain images. The problem of binarization of gray MRI images due to the black background and large intensity variation has been overcome by our proposed method. This method is very useful to extract the objects of interest from an image and, hence, to distinguish the foreground (brain) from the background (black background). The threshold of the image is determined by standard deviation multiplied by a heuristic value. The paper describes the details including the heuristic value used as well as the performance of this method along with some other well known image binarization method.
\end{abstract}

\section{KEYWORDS}

Image Binarization, Performance Evaluation Metrics, Reference Image, Threshold Value, MRI of Brain.

\section{INTRODUCTION:}

Gray scale image and Binary image are two important variations among digital images. In a gray scale image a particular pixel takes a intensity value lying between 0 to 255 where as a binary image it could take only two values either 0 or 1 .The procedure to convert a gray scale image into a binary image is known as image binarization. Image binarization has wide popularity in many research areas especially in case of document image analysis, medical image process and scene processing.

Binarization by Threshold Segmentation of a brain from MRI images is a challenging task. Segmentation and quantification of brain tumor, edma and other disease from MRI of brain need binarization technique as a pre-processing or any other useful steps, so binarization is a very important task for us. There are several binarization techniques or methods which produce very good results for degraded documents, arial image, texture images, and graphic image and shaded image etc, but for MRI many of the existing methods fail due to the large difference of foreground and background intensity. Background part of the image is totally black which have no information and foreground part of the image, the actual brain part have lot of information. In simple cases, binarization can be achieved by thresholding the image, i.e., by assigning all the pixels with gray-level lower than a given threshold to either the background or the foreground, and all the remaining pixels to the other set. However, often more refined processes are required. This is the case when regions with noticeably different gray-levels are all regarded as of interest,

DOI : 10.5121/sipij.2012.3604 
Signal \& Image Processing : An International Journal (SIPIJ) Vol.3, No.6, December 2012

or when regions with the same gray-level can be regarded as belonging to the foreground or to the background, depending on the local context. To binarized MRI images most of the method produces very shocking output. The use of binary images decreases computational load for the overall application. As after binarization we do some needful work for brain edma, tumor detection and quantification like morphological operation, watershed segmentation etc. Thus if poor binarization results produces then their results affect reflected on segmentation. Thus we need techniques which produce meaningful binarization i.e. meaningful information. In this situation i.e. for MRI of brain tumor images our proposed methods gets very good results and produce meaningful information compare to the other well-known method like Otsu [1], Savala[2], Niblack[3], Bernsen[4], Kapur[5] and Otsu as a frame[6] work in iterative partition.

\section{BRIEF REVIEW}

Binarization is the processes of translating a gray-scale image to a binary image by choosing threshold selection method to categorize the pixels of an image into either one of the two classes. Most of the technique are divided into two category global thresholding and local thresholding techniques, in the global thresholding method threshold of the entire image is unique and local thresholding method choose threshold value locally and binarization also local. Otsu[1] and Kapur[5] are two very popular method for global thresholding method and Savala [2], Niblack[3], Bernsen[4] are most popular local thresholding methods. Soharab Hossain Shaikh et all [6] proposed a iterative partitioning method as a framework which produce good results for degradead, graphic documents. Except that Ntogas nikolaos et all [7] proposed a binarization a binarization algorithm for historical manuscripts which produce good result for historical documents. Mehmet Sezgin et all [8] gives a brief survey of image binarization and concept of performance metric. We compare our technique with other well known popular algorithms which are shortly describe.

Otsu Thresholding method, as proposed in [1], is based on discriminate analysis. In this method, the threshold operation is regarded as the partitioning of the pixels of an image into two classes $\mathrm{C}_{0}$ and $\mathrm{C}_{1}$, (e.g., objects and background) at gray level t. That is, $\mathrm{C}_{0}=\{0,1, \ldots, \mathrm{t}\}$ and $\mathrm{C}_{1}=\{\mathrm{t}+1, \mathrm{t}+2, \ldots, 1-\mathrm{L}\}$, where $\mathrm{L}=$ maximum intensity. Let $\sigma_{\mathrm{w}}^{2}, \sigma_{\mathrm{B}}^{2}$ and $\sigma_{\mathrm{T}}^{2}$ be the within-class variance, between-class variance, and the total variance, respectively. An optimal threshold can be determined by minimizing one of the following (equivalent) criterion functions with respect to $\mathrm{t}$ :

$$
\lambda=\frac{\sigma_{\mathrm{B}}^{2}}{\sigma_{\mathrm{w}}^{2}}, \eta=\frac{\sigma_{\mathrm{B}}^{2}}{\sigma_{\mathrm{T}}^{2}}, \mathrm{~K}=\frac{\sigma_{\mathrm{T}}^{2}}{\sigma_{\mathrm{w}}^{2}}
$$

And

Of these three criterion functions, $\eta$ is the simplest. Thus, the optimal threshold $\mathrm{t}^{*}$ is,

$$
\begin{aligned}
& \mathrm{t}^{*}=\operatorname{Arg} \underbrace{\operatorname{MIN} \eta}_{\mathrm{t} \in \mathrm{G}} \\
& \sigma_{\mathrm{T}}^{2}=\sum_{\mathrm{i}=0}^{1-1}\left(\mathrm{i}-\mu_{\mathrm{T}}\right)^{2} \mathrm{P}_{\mathrm{i}}, \quad \mu_{\mathrm{T}}=\sum_{\mathrm{i}=0}^{1-1} \mathrm{iP}_{\mathrm{i}}
\end{aligned}
$$

$$
\sigma_{\mathrm{B}}^{2}=\mathrm{w}_{0} \mathrm{w}_{1}\left(\mathrm{w}_{0} \mathrm{w}_{1}\right)^{2}, \quad \mathrm{w}_{0}=\sum_{\mathrm{i}=0}^{\mathrm{t}} \mathrm{P}_{\mathrm{i}}, \quad \mathrm{w}_{1}=1-\mathrm{w}_{0},
$$




$$
\mu_{1}=\frac{\mu_{\mathrm{T}}-\mu_{\mathrm{t}}}{1-\mathrm{w}_{0}}, \quad \mu_{0}=\frac{\mu_{\mathrm{t}}}{\mathrm{w}_{0}}, \quad \mu_{\mathrm{T}}=\sum_{\mathrm{i}=0}^{\mathrm{t}} \mathrm{P}_{\mathrm{i}},
$$

Kapur's algorithm [5] is an extension of Otsu's method. In this method two probability distributions (e.g. object distributions and background distributions) are derived from the original gray level distributions of the image as;

$$
\frac{P_{0}}{P_{t}}, \frac{P_{1}}{P_{t}}, \ldots, \frac{P_{t}}{P_{t}} \text { and } \frac{P_{t+1}}{1-P_{t}}, \frac{P_{t+2}}{1-P_{t}}, \ldots, \frac{P_{1-1}}{1-P_{t}}
$$

Where $\mathrm{t}$ is the threshold value

$$
\mathrm{P}_{\mathrm{T}}=\sum_{\mathrm{i}=0}^{\mathrm{t}} \mathrm{P}_{\mathrm{i}}
$$

And

$$
H_{b}(t)=-\sum_{i=0}^{t} \frac{P_{i}}{P_{t}} \log _{e} \frac{P_{i}}{P_{t}}, \quad H_{w}(t)=-\sum_{i=t+1}^{L-1} \frac{P_{i}}{1-P_{t}} \log _{e} \frac{P_{i}}{1-P_{t}}
$$

Then the optimal threshold $t^{*}$ is defined as the gray value which maximizes $H_{b}(t)+H_{w}(t)$, that is,

$$
\mathrm{t}^{*}=\operatorname{Arg} \operatorname{Max}_{\mathrm{t} \in \mathrm{G}}\left\{\mathrm{H}_{\mathrm{b}}(\mathrm{t})+\mathrm{H}_{\mathrm{w}}(\mathrm{t})\right\}
$$

Niblack [3] proposed an algorithm that calculates a pixel wise thresholding by shifting a rectangular window across the image. This method varies the threshold over the image, based on the local mean and local standard deviation. Let the local area $b^{*} \mathrm{~b}$. Also the threshold $\mathrm{T}_{\text {nib }}(\mathrm{x}, \mathrm{y})$ at pixel $f(x, y)$ is determined by the equations:

$$
\operatorname{Tnib}(x, y)=\mu \operatorname{nib}(x, y)+K \operatorname{nib} * \sigma_{-} \operatorname{nib}^{\wedge} 2(x, y)
$$

Where,

$$
\left.\mu \operatorname{nib}(x, y)=\frac{1}{b^{2}} \mid \sum_{j=y-b / 2}\left(\sum_{i=x-b / 2} f(i, j)\right)\right\rfloor
$$

and

$$
\sigma_{\text {nib }}^{2}(x, y)=\frac{1}{b^{2}}\left[\sum_{j=y-b / 2}^{y+b / 2}\left(\sum_{i=x-b / 2}^{x+b / 2}\left\{\mu_{\text {nib }}(x, y)-f(i, j)\right)\right]\right.
$$

Here, $\mu_{\text {nib }}(\mathrm{x}, \mathrm{y}) \& \sigma_{\text {nib }}^{2}(\mathrm{x}, \mathrm{y})$ are the local mean and the standard deviation values of local area. The local window size $b$, should be small enough to reflect the local illumination level accurately and adequately large to include both objects and background.

Bernsan's algorithm [4] that method calculates the local threshold value based on the mean value of the minimum and maximum intensities of pixels within a window. If the window is centered at the pixel $(x, y)$ the threshold for $(x, y)$ is defined by: $T(x, y)=\frac{Z_{\max }+Z_{\min }}{2}$ where $Z_{\max }$ and $Z_{\min }$ are the maximum and minimum intensity of the window. This threshold works properly only when the contrast is large. Contrast is defined, $\mathrm{C}(\mathrm{x}, \mathrm{y})=\mathrm{Z}_{\max }-\mathrm{Z}_{\min }$. if the contrast is less that a specific value $\mathrm{K}$, the pixels within the window may be set to background or to foreground according to the class that most suitably describes the window. This algorithm is dependent on $\mathrm{K}$ value and also on the size $\mathrm{N}$ of window $\mathrm{N} * \mathrm{~N}$. 
Sauvola and Pietikainen [2] devised a method that solves Niblack's problem by hypothesizing on the gray values on objects and background pixels, resulting in the following formula for the threshold:

$$
\mathrm{T}_{\mathrm{sa}}(\mathrm{x}, \mathrm{y})=\mu_{\mathrm{sa}}+\left(1-\mathrm{K}_{\mathrm{sa}}\left(1-\frac{\sigma_{\mathrm{sa}}^{2}(\mathrm{x}, \mathrm{y})}{\mathrm{R}}\right)\right)
$$

Where $\mu_{\mathrm{sa}}$ and $\sigma_{\mathrm{sa}}^{2}$ are ine ıocal mean and une stanuara aeviautıon values ol ıocal area, $\mathrm{R}$ denotes the dynamics of the standard deviation fixed to 128 and $\mathrm{K}_{\mathrm{sa}}$ refers to a fixed value usually set to 0.5 .

In spite of the global and local thresholding approaches, we use the partitioning approach [13]. This partitioning method calculates the number of peaks $\mathrm{P}$ in a histogram. If $\mathrm{P}>=2$ then it subdivides the image into four equal sub-images and repeats the tasks until the sub- image becomes bimodal. This task is recursive and reappearance is controlled by a partition parameter partition parameter. If a sub-image has perfectly bimodal histogram then a global thresholding procedure like Otsu [1] is applied on that sub-image.

Mehmet Sezgin and Bulent Sankur [8] gives a survey over image thresholding method which gives to measure by performance metrics and brief discussion about local thresholding, global thresholding, adaptive, non adaptive type of binarization. There are several research on graphic image, degradead text, documented image some of them gives very good results but for MRI of brain images most of the images produces insensitive results. MRI images gives meaningful information for diagonistic purpous. Thus the focus of our paper is to produce an efficient algorithms for MRI of brain images which produce better results than other existing well known algorithms.

\section{PROposed Methodology}

In the proposed methods we used standard deviation to select the threshold intensity of the image. Ultimate selection of threshold has done by multiplying a constant value with the threshold intensity of the image using standard deviation. We use the threshold intensity as global value i.e. the threshold intensity of the entire image is unique. The standard deviation of the image pixel of a image $\mathrm{I}(\mathrm{x}, \mathrm{y})$ or matrix element for $\mathrm{I}(\mathrm{x}, \mathrm{y})$ is given by :

$$
S=\left(\frac{1}{2} \sum_{i=1}^{n}\left(x_{i}-x^{\prime}\right)^{2}\right)^{1 / 2}
$$

Where

$$
x^{\prime}=\left(\frac{1}{n} \sum_{i=1}^{n} x_{i}\right)
$$

The algorithms are written below.

\subsection{Algorithm}

Input: MRI of Brain Image.

Output: Binarizes MRI of Brain Image.

Step1: Take an MRI image I(x,y). 
Signal \& Image Processing : An International Journal (SIPIJ) Vol.3, No.6, December 2012

Step2: If it is color image then convert it into gray scale image $\mathrm{I}_{\mathrm{g}}(\mathrm{x}, \mathrm{y})$.

Step3: Calculate standard deviation of the image and store the intensity value in $\mathrm{T}_{\mathrm{S}}$.

Step4: calculate the threshold value by product of standard deviation and a predefine constant $\mathrm{H}$, i.e.

Threshold intensity value $\mathrm{T}=\mathrm{T}_{\mathrm{S}} * \mathrm{H}$.

Step5: Scan left to right and top to bottom, each pixel of the gray image $\mathrm{I}_{\mathrm{g}}(\mathrm{x}, \mathrm{y})$.

Step6: Find a binary image $I_{B}$ from the gray image $1_{g}(x, y)$ in the following way,

$$
\begin{array}{cc}
\mathrm{I}_{\mathrm{B}}(\mathrm{x}, \mathrm{y})=1 & \mathrm{l}_{\mathrm{g}}(\mathrm{x}, \mathrm{y})>=\mathrm{T} \\
\mathrm{I}_{\mathrm{B}}(\mathrm{x}, \mathrm{y})=0 & \mathrm{l}_{\mathrm{g}}(\mathrm{x}, \mathrm{y})<\mathrm{T}
\end{array}
$$

Step7: $\mathrm{I}_{\mathrm{B}}$ is the output binary image.

Our proposed method is a new binarization technique of MRI of brain that so MRI of brain is used as an input. As the binarization technique can be applied only to grayscale images. We convert RGB image to its corresponding grayscale image. A RGB image has three components red, green and blue and converts it into on component i.e. gray value which lies between 0 to 255 intensity values. Then we calculate the standard deviation of the matrix elements (image pixels).Thus by using standard deviation we select the random intensity values as the standard deviation values will be less than 100 and hence we multiplied the deviated value by a constant value. Here we choose this constant value $\mathrm{H}=3$. Although $\mathrm{H}=3$ is choosen, in few images $\mathrm{H}=2.5$ also produce good results .Here we also gives a comparative study why we choose constant $\mathrm{H}$ equal to 3. Here we use visual inspection as well as quantative measurement to choose the constant. Visual inspection may be biased but together with quantative measurement [8] such as ME, RAE, Precision, Recall, F-measure and visual are very effective. Thus after getting the threshold intensity we compare each pixel of the gray image to find out whether it is greater than or less than the threshold intensity value. If the pixel intensity is greater than the threshold value then that pixel value is set to 1 otherwise it is set to 0 . Thus the whole image is transformed into 0 or 1 i.e. a binary image is generated from the gray image where the foregrounds are marked as 1 and backgrounds are marked as 0 .

As there is no proper reference image creation methodology for MRI of brain image we initially select majority voting scheme as a reference image creation but it has been observed that using majority voting scheme improper reference images are produce in MRI of brain image datasets. So, for MRI of brain images the reference images have been created manually with the help of Software photo editor. From this reference image we measure the parameter like ME, RAE, Recall, Precision, F-Measure which has been describe in the next section. The output of our proposed methodology with different constant value i.e. $\mathrm{H}=2, \mathrm{H}=2.5, \mathrm{H}=3, \mathrm{H}=3.5$ are shown in figure 3; figure 4, figure5, figure 6. Input MRI and its corresponding reference image is shown in figure 1 and figure 2. 
Signal \& Image Processing : An International Journal (SIPIJ) Vol.3, No.6, December 2012

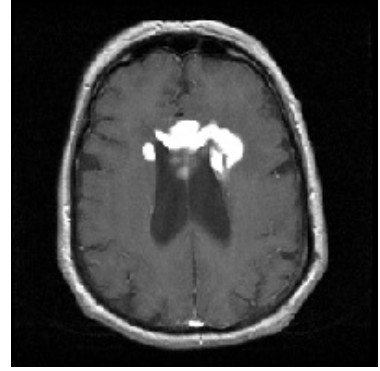

Figure1: MRI of Brain

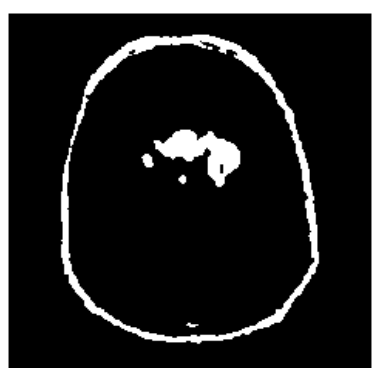

Figure4: Binarize output with $\mathrm{H}=2.5$

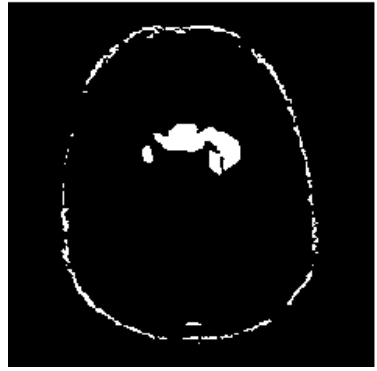

Figure2: Reference image

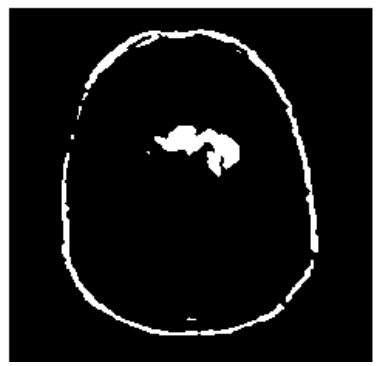

Figure5: Binarize output with $\mathrm{H}=3$

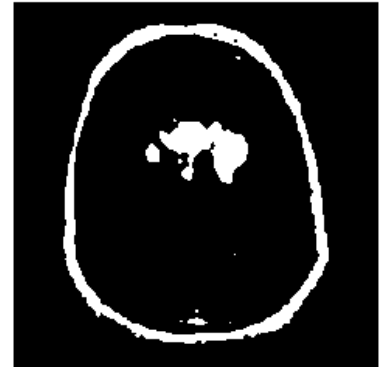

Figure3: Binarize output with $\mathrm{H}=2$

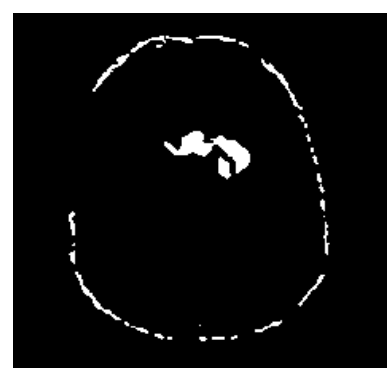

Figure6: Binarize output with $\mathrm{H}=3.5$

\subsection{Evaluation techniques for constant $H$ selection}

We can select constant $\mathrm{H}$ from visual observation but visual observation may be biased so we use some metric such as ME, RAE, Precision, Recall, F-measure.

Misclassification error (ME): Misclassification error [8] gives us the percentage of background pixels wrongly assigned to foreground, and conversely. ME can expressed in the following equation of the two-class segmentation problems:

$$
M E=1-\frac{|\mathrm{BO} \cap \mathrm{BT}|+|\mathrm{FO} \cap \mathrm{FT}|}{|\mathrm{BO}|+|\mathrm{FO}|}
$$

where B0 and F0 denote the background area pixel and foreground area pixels of the original reference image and BT and FT denote the background area pixel and foreground area pixels in the test image, and $\mathrm{I} . \mathrm{I}$ is the cardinality of the set. Thus lesser the ME for a technique better is the result.

Relative Foreground Area Error (RAE): Relative Foreground Area Error (RAE) [8] is based on a measure for the area ; the RAE is stated below in the following equation:

$$
R A E= \begin{cases}\frac{\mathrm{A} 0-\mathrm{AT}}{\mathrm{A} 0} & \text { if } \mathrm{AT}<A 0 \\ \frac{\mathrm{AT}-\mathrm{A} 0}{\mathrm{AT}} & \text { if } \mathrm{AT} \geq \mathrm{A} 0\end{cases}
$$

Here, A0 is the area of original reference image, and AT is the area of thresholded binarized image. Thus lesser RAE means better binarization.

Recall, Precision and F-measure [8]: In the context of binarization, the recall, precision and Fmeasure are defined as , 
Signal \& Image Processing : An International Journal (SIPIJ) Vol.3, No.6, December 2012

N_Relevant $=$ Number of object pixels in the Reference Image.

N_Retrieved $=$ Number object pixels in the Binary Image.

$\mathrm{A}=$ Number of object pixels intersect between Reference and the Binary Image.

$\mathrm{B}=\mathrm{N} \_$Relevant $-\mathrm{A}, \quad \mathrm{C}=\mathrm{N} \_$Retrieved $-\mathrm{A}$ and Recall $=\frac{\mathrm{A}}{\mathrm{A}+\mathrm{B}}$, Precision $=\frac{\mathrm{A}}{\mathrm{A}+\mathrm{C}}$

A measure that combines precision and recall is the harmonic mean of precision and recall, the traditional F-measure. It is defined as follows:

$$
F \text {-measure }=\frac{2 \times \text { Recall } \times \text { Precision }}{\text { Recall }+ \text { Precision }}
$$

A higher value of F-measure indicates better performance.

Thus the table for ME, RAE, Precision, Recall, F-measure on different MRI of brain is shown below.

Table 1: ME measurement

\begin{tabular}{|c|c|c|c|c|}
\hline Image name & $\mathrm{H}=2$ & $\mathrm{H}=2.5$ & $\mathrm{H}=3$ & $\mathrm{H}=3.5$ \\
\hline MRI_1 & 0.0702 & 0.0331 & 0.0245 & 0.0168 \\
\hline MRI_2 & 0.0252 & 0.0340 & 0.0524 & 0.0841 \\
\hline MRI_3 & 0.2608 & 0.0292 & 0.0051 & 0.0081 \\
\hline MRI_4 & 0.0500 & 0.0253 & 0.0117 & 0.0344 \\
\hline MRI_5 & 0.2188 & 0.0332 & 0.0051 & 0.0195 \\
\hline MRI_6 & 0.1058 & 0.0176 & 0.0090 & 0.0236 \\
\hline MRI_7 & 0.3358 & 0.0246 & 0.0098 & 0.0116 \\
\hline MRI_8 & 0.0608 & 0.0385 & 0.0221 & 0.0098 \\
\hline MRI_9 & 0.1091 & 0.0470 & 0.0108 & 0.0180 \\
\hline MRI_10 & 0.1077 & 0.0340 & 0.0210 & 0.0273 \\
\hline MRI_11 & 0.2075 & 0.0483 & 0.0086 & 0.0048 \\
\hline MRI_12 & 0.3144 & 0.0954 & 0.0265 & 0.0361 \\
\hline MRI_13 & 0.1745 & 0.0964 & 0.0225 & 0.0056 \\
\hline MRI_14 & 0.1387 & 0.0168 & 0.0053 & 0.0159 \\
\hline MRI_15 & 0.0532 & 0.0153 & 0.0252 & 0.0411 \\
\hline MRI_16 & 0.0212 & 0.0157 & 0.0071 & 0.0155 \\
\hline MRI_17 & 0.0844 & 0.0433 & 0.0077 & 0.0217 \\
\hline
\end{tabular}

Table 2: RAE measurement

\begin{tabular}{|c|c|c|c|c|}
\hline Image name & $\mathrm{H}=2$ & $\mathrm{H}=2.5$ & $\mathrm{H}=3$ & $\mathrm{H}=3.5$ \\
\hline MRI_1 & 0.7401 & 0.5622 & 0.4475 & 0.2543 \\
\hline MRI_2 & 0.0217 & 0.2419 & 0.4415 & 0.7260 \\
\hline MRI_3 & 0.9588 & 0.7222 & 0.4578 & 0.7193 \\
\hline MRI_4 & 0.3646 & 0.2005 & 0.0445 & 0.3984 \\
\hline MRI_5 & 0.6829 & 0.2424 & 0.0131 & 0.1908 \\
\hline MRI_6 & 0.7444 & 0.3136 & 0.0916 & 0.6501 \\
\hline MRI_7 & 0.9570 & 0.5735 & 0.0010 & 0.7737 \\
\hline MRI_8 & 0.6515 & 0.5364 & 0.3506 & 0.1670 \\
\hline
\end{tabular}


Signal \& Image Processing : An International Journal (SIPIJ) Vol.3, No.6, December 2012

\begin{tabular}{|c|l|l|l|l|}
\hline MRI_9 & 0.6494 & 0.4387 & 0.0840 & 0.3050 \\
\hline MRI_10 & 0.8090 & 0.5695 & 0.3982 & 0.2757 \\
\hline MRI_11 & 0.9382 & 0.7793 & 0.3838 & 0.2546 \\
\hline MRI_12 & 0.8849 & 0.6880 & 0.0257 & 0.8818 \\
\hline MRI_13 & 0.9533 & 0.9186 & 0.7250 & 0.3939 \\
\hline MRI_14 & 0.8380 & 0.3846 & 0.1986 & 0.5948 \\
\hline MRI_15 & 0.3990 & 0.0448 & 0.3447 & 0.5614 \\
\hline MRI_16 & 0.2566 & 0.2039 & 0.1041 & 0.2514 \\
\hline MRI_17 & 0.6610 & 0.4997 & 0.1783 & 0.5007 \\
\hline
\end{tabular}

Table 3 : Recall measurement

\begin{tabular}{|c|c|c|c|c|}
\hline Image name & $\mathrm{H}=2$ & $\mathrm{H}=2.5$ & $\mathrm{H}=3$ & $\mathrm{H}=3.5$ \\
\hline MRI_1 & 100 & 97.0916 & 90.9035 & 83.0446 \\
\hline MRI_2 & 88.0501 & 73.2279 & 55.2964 & 27.4045 \\
\hline MRI_3 & 100 & 99.7275 & 54.2234 & 28.0654 \\
\hline MRI_4 & 99.7705 & 97.8817 & 90.9797 & 60.1589 \\
\hline MRI_5 & 99.8044 & 99.6389 & 98.1342 & 80.8607 \\
\hline MRI_6 & 100 & 98.6140 & 83.0323 & 34.9853 \\
\hline MRI_7 & 91.9470 & 84.9134 & 67.2783 & 22.6300 \\
\hline MRI_8 & 100 & 98.7336 & 93.0582 & 76.5478 \\
\hline MRI_9 & 100 & 99.1708 & 95.4133 & 69.4480 \\
\hline MRI_10 & 99.4582 & 99.0367 & 91.6315 & 32.2697 \\
\hline MRI_11 & 100 & 99.8884 & 99.6652 & 99.6652 \\
\hline MRI_12 & 100 & 93.6218 & 66.2812 & 11.8239 \\
\hline MRI_13 & 100 & 100 & 100 & 100 \\
\hline MRI_14 & 100 & 100 & 80.1366 & 40.5236 \\
\hline MRI_15 & 96.8952 & 87.3099 & 65.5345 & 43.8633 \\
\hline MRI_16 & 100 & 100 & 100 & 74.3358 \\
\hline MRI_17 & 100 & 100 & 82.1705 & 49.9295 \\
\hline
\end{tabular}

Table 4 : Precision measurement

\begin{tabular}{|c|c|c|c|c|}
\hline Image name & $\mathrm{H}=2$ & $\mathrm{H}=2.5$ & $\mathrm{H}=3$ & $\mathrm{H}=3.5$ \\
\hline MRI_1 & 25.9932 & 42.5088 & 50.2222 & 61.9289 \\
\hline MRI_2 & 90.0067 & 96.5937 & 99.0092 & 100 \\
\hline MRI_3 & 4.1174 & 27.7063 & 100 & 100 \\
\hline MRI_4 & 63.3988 & 78.2529 & 95.2152 & 100 \\
\hline MRI_5 & 31.6445 & 75.4902 & 96.8518 & 99.9256 \\
\hline MRI_6 & 25.5637 & 67.6852 & 91.4008 & 100 \\
\hline MRI_7 & 3.9515 & 36.2174 & 67.2098 & 100 \\
\hline MRI_8 & 34.8537 & 45.7708 & 60.4325 & 91.8919 \\
\hline
\end{tabular}


Signal \& Image Processing : An International Journal (SIPIJ) Vol.3, No.6, December 2012

\begin{tabular}{|c|c|c|c|c|}
\hline MRI_9 & 35.0563 & 55.6655 & 87.3962 & 99.9254 \\
\hline MRI_10 & 18.9929 & 42.6387 & 55.1449 & 44.5553 \\
\hline MRI_11 & 6.1810 & 22.0498 & 61.4168 & 74.2928 \\
\hline MRI_12 & 11.5148 & 29.2132 & 68.0322 & 100 \\
\hline MRI_13 & 4.6671 & 8.1407 & 27.5049 & 60.6061 \\
\hline MRI_14 & 16.1980 & 61.5412 & 100 & 100 \\
\hline MRI_15 & 58.2342 & 91.4049 & 100 & 100 \\
\hline MRI_16 & 74.3358 & 79.6088 & 89.5931 & 100 \\
\hline MRI_17 & 33.9028 & 50.0264 & 100 & 100 \\
\hline
\end{tabular}

Table 5 : F - measure

\begin{tabular}{|c|c|c|c|c|}
\hline Image name & $\mathrm{H}=2$ & $\mathrm{H}=2.5$ & $\mathrm{H}=3$ & $\mathrm{H}=3.5$ \\
\hline MRI_1 & 41.2613 & 59.1295 & 64.6994 & 70.9490 \\
\hline MRI_2 & 89.0176 & 83.3034 & 70.9612 & 43.0196 \\
\hline MRI_3 & 7.9091 & 43.3649 & 70.3180 & 43.8298 \\
\hline MRI_4 & 77.5309 & 86.9736 & 93.0493 & 75.1240 \\
\hline MRI_5 & 48.0530 & 85.8996 & 97.4888 & 89.3879 \\
\hline MRI_6 & 40.7183 & 80.2735 & 87.0158 & 51.8357 \\
\hline MRI_7 & 7.5773 & 50.7772 & 67.2440 & 36.9077 \\
\hline MRI_8 & 51.6911 & 62.5464 & 73.2779 & 83.5210 \\
\hline MRI_9 & 51.9136 & 71.3061 & 91.2289 & 81.9447 \\
\hline MRI_10 & 31.8950 & 59.6122 & 68.8532 & 37.4302 \\
\hline MRI_11 & 11.6424 & 36.1251 & 76.00 & 85.1287 \\
\hline MRI_12 & 20.6517 & 44.5312 & 67.1453 & 21.1474 \\
\hline MRI_13 & 8.9179 & 15.0558 & 43.1433 & 75.4717 \\
\hline MRI_14 & 27.8800 & 76.1925 & 88.9731 & 57.6752 \\
\hline MRI_15 & 72.7472 & 89.3105 & 79.1793 & 60.9791 \\
\hline MRI_16 & 85.2789 & 88.6469 & 94.5109 & 85.6210 \\
\hline MRI_17 & 50.6379 & 66.6902 & 90.2128 & 66.6040 \\
\hline
\end{tabular}

Thus from visual inspection and metric dependent evaluation we choose the $\mathrm{H}=3$ as the constant value but some images which have low intensity may have to choose $\mathrm{H}=2.5$ as a constant. For $\mathrm{H}=2$ some extra portion are binarized and for $\mathrm{H}=3.5$ binarization are not effective due to high threshold value.

\section{RESULT \& COMPARISON WITH OTHER WELL-KNOWN METHODOLOGY}

We compare our proposed methodology with other existing well known binarization like Otsu, Niblack, Otsu as a partition framework, Savala, Bernsen, and Kapur methods visually as well as metric wise. Our proposed method produces very good results for MRI of brain. Most of the image produce result or binaries the total image but MRI of brain proceeds by a dark background, we want to binarize the actual brain portion. The global threshold segmentation Kapur produce good results and global thresholding methods Otsu satisfactory but local thresholding method like Savala, Niblack are not suitable for this type of image. For some of the images local thresholding method Bernsen produce satisfactory results. Partitioning framework method do not produce 
Signal \& Image Processing : An International Journal (SIPIJ) Vol.3, No.6, December 2012

good results. Our proposed method is a global thresholding methods produces very good results for MRI of brain. From the metric ME, RAE is less in our proposed method and F-measure are greater value which is expected. Thus our proposed method is very good and efficient algorithms for binarization of MRI of brain. We show the output of different method for the image shown in figure 1 and also shown below proposed method with other existing method for other images.

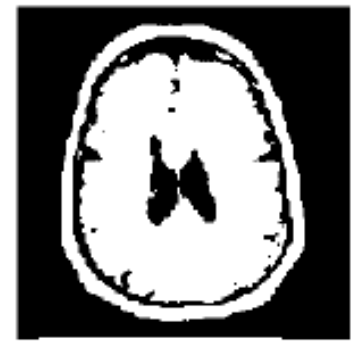

Figure 7: Otsu

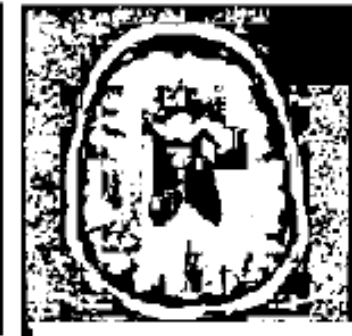

Figure 8: Otsu as a partition

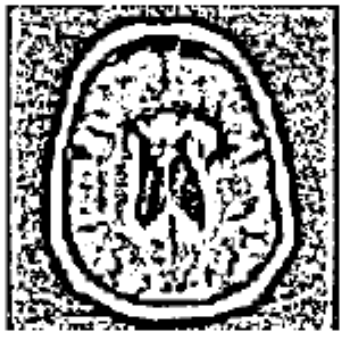

Figure 9: Niblack

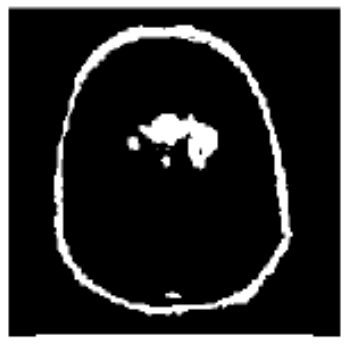

Figure 10: Bernsen

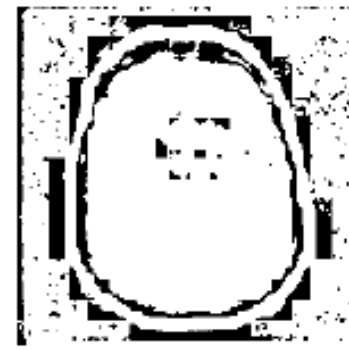

Figure 11: Savala

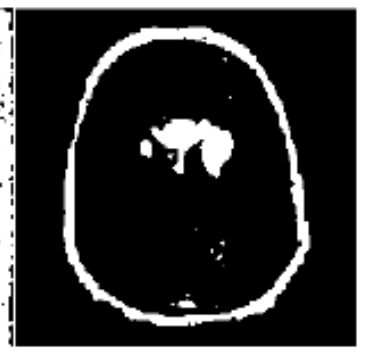

Figure 12: Kapur

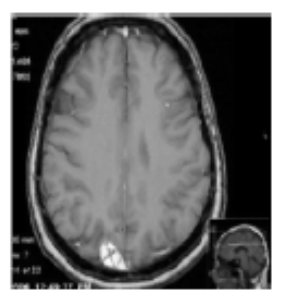

Figure 13: MRI of Brain

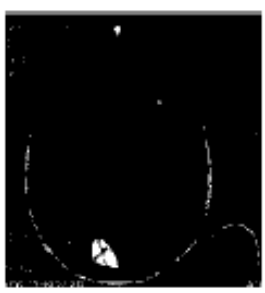

Figure 14:

Reference image

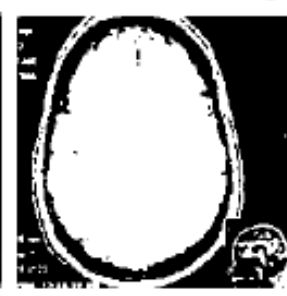

Figure 15:

Otsu

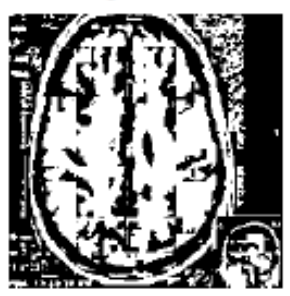

Figure 16: Otsu as a partition

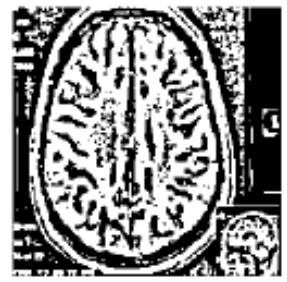

Figure 17: Niblack

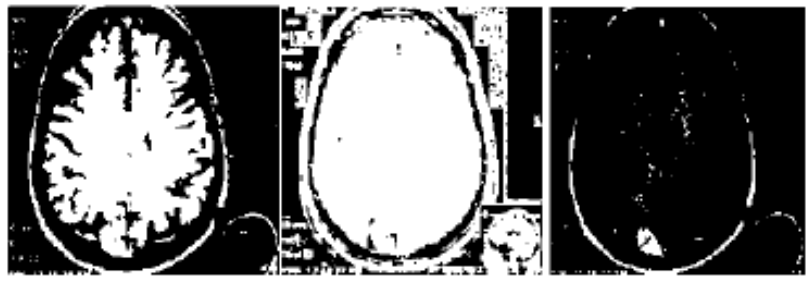

Figure 18: Bernsen

Figure 19: Savala

Figure 20: Kapur

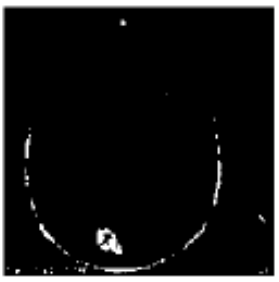

Figure 21: Proposed

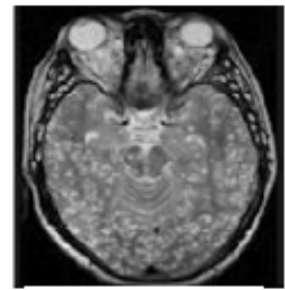

Figure 22: MRI of Brain

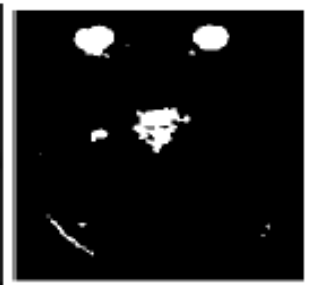

Figure 23: Reference image

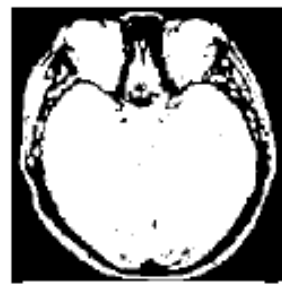

Figure 24: Otsu

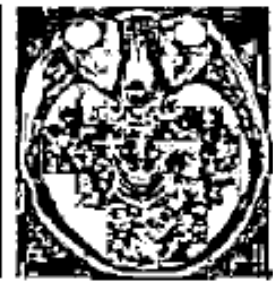

Figure 25: Otsu as a Figure 26: Niblack partition

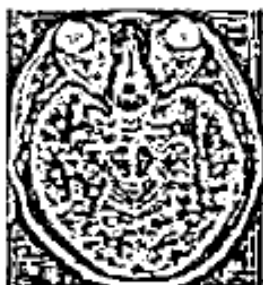


Signal \& Image Processing : An International Journal (SIPIJ) Vol.3, No.6, December 2012

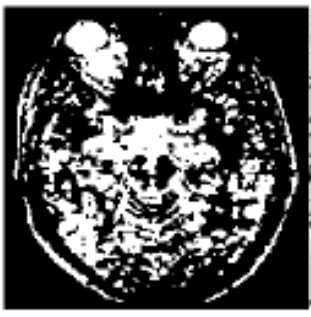

Figure 27: Bernsen

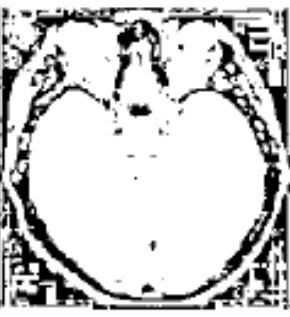

Figure 28: Savala

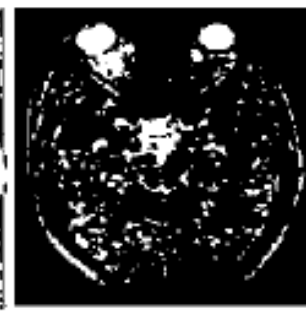

Figure 29: Kapur

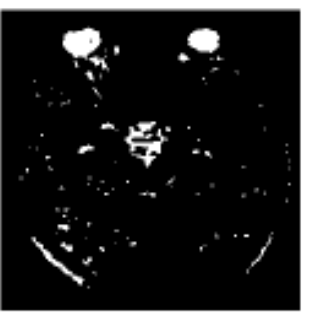

Figure 30: Proposed

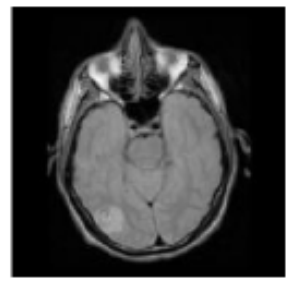

Figure 31: MRI of Brain

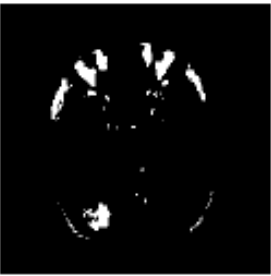

Figure 32: Reference image

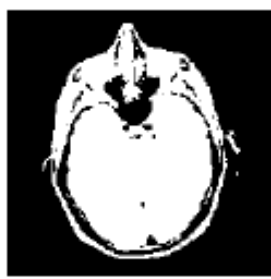

Figure 33: Otsu

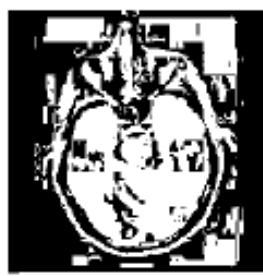

Figure 34: Otsu as a partition

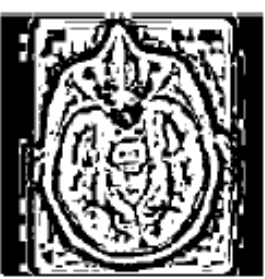

Figure 35: Niblack

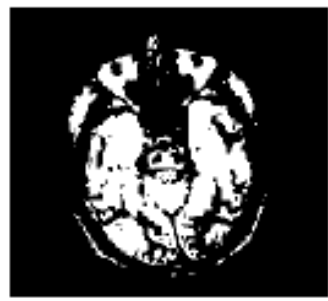

Figure 36: Bernsen

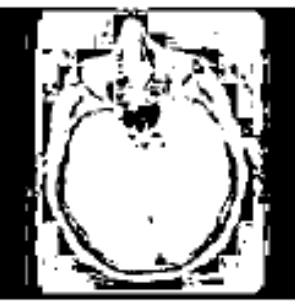

Figure 37: Savala

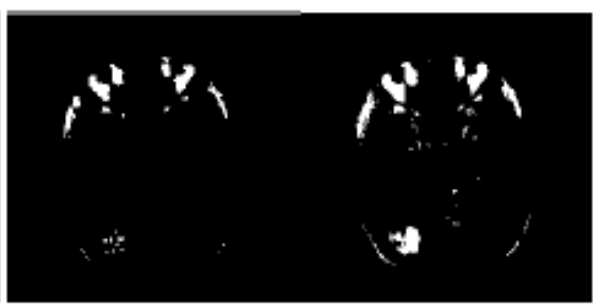

Figure 38: Kapur

Figure 39: Proposed

Table 6 : ME Measurement

\begin{tabular}{|l|l|l|l|l|l|l|l|}
\hline $\begin{array}{l}\text { Image } \\
\text { name }\end{array}$ & $\begin{array}{l}\text { Kapur } \\
\text { Method }\end{array}$ & $\begin{array}{l}\text { Otsu as a } \\
\text { partition }\end{array}$ & $\begin{array}{l}\text { Otsu } \\
\text { Method }\end{array}$ & $\begin{array}{l}\text { Niblack } \\
\text { Method }\end{array}$ & $\begin{array}{l}\text { Bernsen } \\
\text { Method }\end{array}$ & $\begin{array}{l}\text { Savala } \\
\text { Method }\end{array}$ & $\begin{array}{l}\text { Proposd } \\
\text { Method }\end{array}$ \\
\hline MRI_1 & 0.0424 & 0.3763 & 0.3621 & 0.4527 & 0.0399 & 0.6975 & 0.0242 \\
\hline MRI_2 & 0.0403 & 0.4183 & 0.0272 & 0.3426 & 0.0255 & 0.6957 & 0.0514 \\
\hline MRI_3 & 0.0051 & 0.4373 & 0.3783 & 0.4773 & 0.3250 & 0.8811 & 0.0044 \\
\hline MRI_4 & 0.0665 & 0.4171 & 0.0442 & 0.4879 & 0.0526 & 0.6907 & 0.0113 \\
\hline MRI_5 & 0.5156 & 0.4333 & 0.4496 & 0.4849 & 0.2280 & 0.7004 & 0.0043 \\
\hline MRI_6 & 0.0376 & 0.2553 & 0.3969 & 0.2844 & 0.1207 & 0.4175 & 0.0090 \\
\hline MRI_7 & 0.0255 & 0.4399 & 0.5172 & 0.4777 & 0.3332 & 0.6460 & 0.0053 \\
\hline MRI_8 & 0.0627 & 0.4633 & 0.3939 & 0.5184 & 0.0475 & 0.7412 & 0.0218 \\
\hline MRI_9 & 0.0857 & 0.5142 & 0.6194 & 0.4839 & 0.0971 & 0.7719 & 0.0105 \\
\hline MRI_10 & 0.0485 & 0.5418 & 0.3674 & 0.4088 & 0.0296 & 0.8716 & 0.0226 \\
\hline MRI_11 & 0.0110 & 0.4013 & 0.3515 & 0.5228 & 0.0290 & 0.8778 & 0.0103 \\
\hline MRI_12 & 0.0695 & 0.4360 & 0.5460 & 0.5063 & 0.2354 & 0.7459 & 0.0265 \\
\hline MRI_13 & 0.0149 & 0.3914 & 0.2874 & 0.5441 & 0.0473 & 0.8522 & 0.0267 \\
\hline MRI_14 & 0.0203 & 0.3661 & 0.4300 & 0.3818 & 0.1344 & 0.5000 & 0.0047 \\
\hline MRI_15 & 0.0440 & 0.2691 & 0.2807 & 0.3429 & 0.0759 & 0.4161 & 0.0149 \\
\hline MRI_16 & 0.0461 & 0.1984 & 0.0236 & 0.2979 & 0.0327 & 0.4618 & 0.0071 \\
\hline MRI_17 & 0.0105 & 0.4257 & 0.1507 & 0.4993 & 0.0117 & 0.7222 & 0.0077 \\
\hline
\end{tabular}


Signal \& Image Processing : An International Journal (SIPIJ) Vol.3, No.6, December 2012

Table 7: RAE Measurement

\begin{tabular}{|l|l|l|l|l|l|l|l|}
\hline $\begin{array}{l}\text { Image } \\
\text { name }\end{array}$ & $\begin{array}{l}\text { Kapur } \\
\text { Method }\end{array}$ & $\begin{array}{l}\text { Otsu as a } \\
\text { partition }\end{array}$ & $\begin{array}{l}\text { Otsu } \\
\text { Method }\end{array}$ & $\begin{array}{l}\text { Niblack } \\
\text { Method }\end{array}$ & $\begin{array}{l}\text { Bernsen } \\
\text { Method }\end{array}$ & $\begin{array}{l}\text { Savala } \\
\text { Method }\end{array}$ & $\begin{array}{l}\text { Proposed } \\
\text { Method }\end{array}$ \\
\hline MRI_1 & 0.6470 & 0.9378 & 0.9363 & 0.9363 & 0.6160 & 0.9662 & 0.4475 \\
\hline MRI_2 & 0.2535 & 0.7969 & 0.1247 & 0.7127 & 0.1159 & 0.8585 & 0.4415 \\
\hline MRI_3 & 0.3075 & 0.9782 & 0.9713 & 0.9766 & 0.9669 & 0.9875 & 0.4578 \\
\hline MRI_4 & 0.4280 & 0.8481 & 0.3227 & 0.8510 & 0.3646 & 0.8918 & 0.0445 \\
\hline MRI_5 & 0.8345 & 0.8120 & 0.8195 & 0.8252 & 0.6902 & 0.8746 & 0.0131 \\
\hline MRI_6 & 0.4834 & 0.8713 & 0.9169 & 0.8850 & 0.7935 & 0.9206 & 0.0916 \\
\hline MRI_7 & 0.5735 & 0.9680 & 0.9720 & 0.9700 & 0.9579 & 0.9780 & 0.0010 \\
\hline MRI_8 & 0.6574 & 0.9377 & 0.9243 & 0.9414 & 0.6094 & 0.9597 & 0.3506 \\
\hline MRI_9 & 0.5988 & 0.8977 & 0.9133 & 0.8915 & 0.6147 & 0.9294 & 0.0840 \\
\hline MRI_10 & 0.6531 & 0.9554 & 0.9359 & 0.9408 & 0.5457 & 0.9719 & 0.3982 \\
\hline MRI_11 & 0.4452 & 0.9705 & 0.9627 & 0.9743 & 0.6470 & 0.9848 & 0.3838 \\
\hline MRI_12 & 0.5996 & 0.9118 & 0.9303 & 0.9240 & 0.8518 & 0.9480 & 0.0257 \\
\hline MRI_13 & 0.5566 & 0.9784 & 0.9707 & 0.9844 & 0.8344 & 0.9900 & 0.7250 \\
\hline MRI_14 & 0.2778 & 0.9300 & 0.9400 & 0.9327 & 0.8227 & 0.9481 & 0.1986 \\
\hline MRI_15 & 0.2995 & 0.7779 & 0.7864 & 0.8188 & 0.4674 & 0.8469 & 0.3447 \\
\hline MRI_16 & 0.4283 & 0.7521 & 0.2774 & 0.8201 & 0.5324 & 0.8825 & 0.1041 \\
\hline MRI_17 & 0.2435 & 0.9077 & 0.7768 & 0.9201 & 0.2692 & 0.9434 & 0.1783 \\
\hline
\end{tabular}

Table 8: Recall Measurement

\begin{tabular}{|l|l|l|l|l|l|l|l|}
\hline $\begin{array}{l}\text { Image } \\
\text { name }\end{array}$ & $\begin{array}{l}\text { Kapur } \\
\text { Method }\end{array}$ & $\begin{array}{l}\text { Otsu as a } \\
\text { partition }\end{array}$ & $\begin{array}{l}\text { Otsu } \\
\text { Method }\end{array}$ & $\begin{array}{l}\text { Niblack } \\
\text { Method }\end{array}$ & $\begin{array}{l}\text { Bernsen } \\
\text { Method }\end{array}$ & $\begin{array}{l}\text { Savala } \\
\text { Method }\end{array}$ & $\begin{array}{l}\text { Proposed } \\
\text { Method }\end{array}$ \\
\hline MRI_1 & 99.9381 & 98.6386 & 100 & 100 & 99.5668 & 100 & 90.9035 \\
\hline MRI_2 & 97.6680 & 93.0435 & 95.2174 & 89.6047 & 82.8063 & 99.8682 & 55.2964 \\
\hline MRI_3 & 96.5940 & 90.4632 & 100 & 98.6376 & 100 & 100 & 54.2234 \\
\hline MRI_4 & 99.8941 & 96.1518 & 99.5587 & 93.3098 & 99.7705 & 100 & 90.9797 \\
\hline MRI_5 & 99.8947 & 98.1794 & 99.8646 & 97.3819 & 99.8044 & 99.8345 & 98.1342 \\
\hline MRI_6 & 99.9580 & 97.6900 & 100 & 94.4141 & 100 & 100 & 83.0323 \\
\hline MRI_7 & 84.9134 & 93.9857 & 97.8593 & 96.1264 & 92.1509 & 98.8787 & 67.2783 \\
\hline MRI_8 & 100 & 97.5610 & 100 & 98.6867 & 99.9531 & 100 & 93.0582 \\
\hline MRI_9 & 100 & 99.3003 & 100 & 99.8445 & 100 & 100 & 95.4133 \\
\hline MRI_10 & 99.0367 & 99.6388 & 100 & 90.6081 & 99.0367 & 100 & 91.6315 \\
\hline MRI_11 & 99.6652 & 100 & 100 & 92.4107 & 99.8884 & 100 & 99.6652 \\
\hline MRI_12 & 89.8545 & 83.9239 & 100 & 89.1085 & 99.6270 & 100 & 66.2812 \\
\hline MRI_13 & 100 & 100 & 100 & 100 & 100 & 100 & 100 \\
\hline MRI_14 & 100 & 100 & 100 & 100 & 100 & 100 & 80.1366 \\
\hline MRI_15 & 95.5407 & 96.2909 & 100 & 98.4788 & 97.8120 & 99.3749 & 65.5345 \\
\hline MRI_16 & 100 & 90.3202 & 100 & 85.6540 & 46.7610 & 100 & 100 \\
\hline MRI_17 & 75.6519 & 99.9648 & 100 & 98.8724 & 73.0796 & 100 & 82.1705 \\
\hline
\end{tabular}


Signal \& Image Processing : An International Journal (SIPIJ) Vol.3, No.6, December 2012

Table 9 : Precision Measurement

\begin{tabular}{|l|l|l|l|l|l|l|l|}
\hline $\begin{array}{l}\text { Image } \\
\text { name }\end{array}$ & $\begin{array}{l}\text { Kapur } \\
\text { Method }\end{array}$ & $\begin{array}{l}\text { Otsu as a } \\
\text { partition }\end{array}$ & $\begin{array}{l}\text { Otsu } \\
\text { Method }\end{array}$ & $\begin{array}{l}\text { Niblack } \\
\text { Method }\end{array}$ & $\begin{array}{l}\text { Bernsen } \\
\text { Method }\end{array}$ & $\begin{array}{l}\text { Savala } \\
\text { Method }\end{array}$ & $\begin{array}{l}\text { Proposed } \\
\text { Method }\end{array}$ \\
\hline MRI_1 & 35.2774 & 6.1400 & 6.3695 & 5.1980 & 38.2367 & 3.3808 & 50.2222 \\
\hline MRI_2 & 72.9124 & 18.8965 & 83.3468 & 25.7477 & 93.6662 & 14.1310 & 99.0092 \\
\hline MRI_3 & 66.8868 & 1.9709 & 2.8729 & 2.3037 & 3.3103 & 1.2491 & 100 \\
\hline MRI_4 & 57.1385 & 14.6032 & 67.4319 & 13.8999 & 63.3988 & 10.8171 & 95.2152 \\
\hline MRI_5 & 16.5293 & 18.4541 & 18.0206 & 17.0231 & 30.9173 & 12.5205 & 96.8518 \\
\hline MRI_6 & 51.6381 & 12.5771 & 8.3075 & 10.8610 & 20.6451 & 7.9404 & 91.4008 \\
\hline MRI_7 & 36.2174 & 3.0070 & 2.7381 & 2.8831 & 3.8777 & 2.1777 & 67.2098 \\
\hline MRI_8 & 34.2600 & 6.0760 & 7.5724 & 5.7877 & 39.0436 & 4.0338 & 60.4325 \\
\hline MRI_9 & 40.1185 & 10.1566 & 8.6704 & 10.8334 & 38.5322 & 7.0604 & 87.3962 \\
\hline MRI_10 & 34.3567 & 4.4394 & 6.4104 & 5.3654 & 44.9945 & 2.8100 & 55.1449 \\
\hline MRI_11 & 55.2941 & 2.9505 & 3.7346 & 2.3705 & 35.2640 & 1.5217 & 61.4168 \\
\hline MRI_12 & 35.9821 & 7.4033 & 6.9702 & 6.7721 & 14.7651 & 5.1994 & 68.0322 \\
\hline MRI_13 & 44.3389 & 2.1590 & 2.9292 & 1.5580 & 16.5582 & 0.9976 & 27.5049 \\
\hline MRI_14 & 72.2154 & 7.0020 & 6.0007 & 6.7256 & 17.7331 & 5.1876 & 100 \\
\hline MRI_15 & 66.9245 & 21.3886 & 21.3574 & 17.8441 & 52.0977 & 15.2179 & 100 \\
\hline MRI_16 & 57.1733 & 22.3911 & 72.2561 & 15.4097 & 100 & 11.7494 & 89.5931 \\
\hline MRI_17 & 100 & 9.2311 & 22.3218 & 7.9047 & 100 & 5.6569 & 100 \\
\hline
\end{tabular}

Table 10: F Measure Measurement

\begin{tabular}{|l|l|l|l|l|l|l|l|}
\hline $\begin{array}{l}\text { Image } \\
\text { name }\end{array}$ & $\begin{array}{l}\text { Kapur } \\
\text { Method }\end{array}$ & $\begin{array}{l}\text { Otsu as a } \\
\text { partition }\end{array}$ & $\begin{array}{l}\text { Otsu } \\
\text { Method }\end{array}$ & $\begin{array}{l}\text { Niblack } \\
\text { Method }\end{array}$ & $\begin{array}{l}\text { Bernsen } \\
\text { Method }\end{array}$ & $\begin{array}{l}\text { Savala } \\
\text { Method }\end{array}$ & $\begin{array}{l}\text { Proposed } \\
\text { Method }\end{array}$ \\
\hline MRI_1 & 52.1472 & 11.5604 & 11.9761 & 9.8823 & 55.2541 & 6.5405 & 64.6994 \\
\hline MRI_2 & 83.4938 & 31.4132 & 88.8875 & 40.0012 & 87.9021 & 24.7587 & 70.9612 \\
\hline MRI_3 & 79.0412 & 3.8577 & 5.5854 & 4.5022 & 6.4085 & 2.4674 & 70.3180 \\
\hline MRI_4 & 72.6957 & 25.3555 & 80.4049 & 24.1955 & 77.5309 & 19.5224 & 93.0493 \\
\hline MRI_5 & 28.3651 & 31.0685 & 30.5318 & 28.9802 & 47.2100 & 22.2505 & 97.4888 \\
\hline MRI_6 & 68.0973 & 22.2850 & 15.3405 & 19.4809 & 34.2245 & 14.7125 & 87.0158 \\
\hline MRI_7 & 50.7772 & 5.8275 & 5.3271 & 5.5983 & 7.4422 & 4.2615 & 67.2440 \\
\hline MRI_8 & 51.0353 & 11.4396 & 14.0786 & 10.9341 & 56.1528 & 7.7547 & 73.2779 \\
\hline MRI_9 & 57.2637 & 18.4284 & 15.9572 & 19.5460 & 55.6292 & 13.1896 & 91.2289 \\
\hline MRI_10 & 51.0157 & 8.5000 & 12.0485 & 10.1309 & 61.8770 & 5.4664 & 68.8532 \\
\hline MRI_11 & 71.1270 & 5.7318 & 7.2003 & 4.6223 & 52.1258 & 2.9979 & 76.000 \\
\hline MRI_12 & 51.3865 & 13.6063 & 13.0320 & 12.5876 & 25.7185 & 9.8848 & 67.1453 \\
\hline MRI_13 & 61.4372 & 4.2267 & 5.6916 & 3.0682 & 28.4120 & 1.9755 & 43.1433 \\
\hline MRI_14 & 83.8663 & 13.0875 & 11.3220 & 12.6036 & 30.1243 & 9.8636 & 88.9731 \\
\hline MRI_15 & 78.7124 & 35.0023 & 35.1975 & 30.2135 & 67.9846 & 26.3940 & 79.1793 \\
\hline MRI_16 & 72.7519 & 35.8858 & 83.8938 & 26.1202 & 63.7240 & 21.0282 & 94.5109 \\
\hline MRI_17 & 86.1384 & 16.9015 & 36.4969 & 14.6390 & 84.4463 & 10.7080 & 90.2128 \\
\hline & & & & & & & \\
\hline
\end{tabular}

Figure below shows the graphical representation of ME, RAE, Recall, Precision, F measure of different method with different color representation. Vertical axis represent measurement value and horizontal axis represent different image with different methods. 
Signal \& Image Processing : An International Journal (SIPIJ) Vol.3, No.6, December 2012

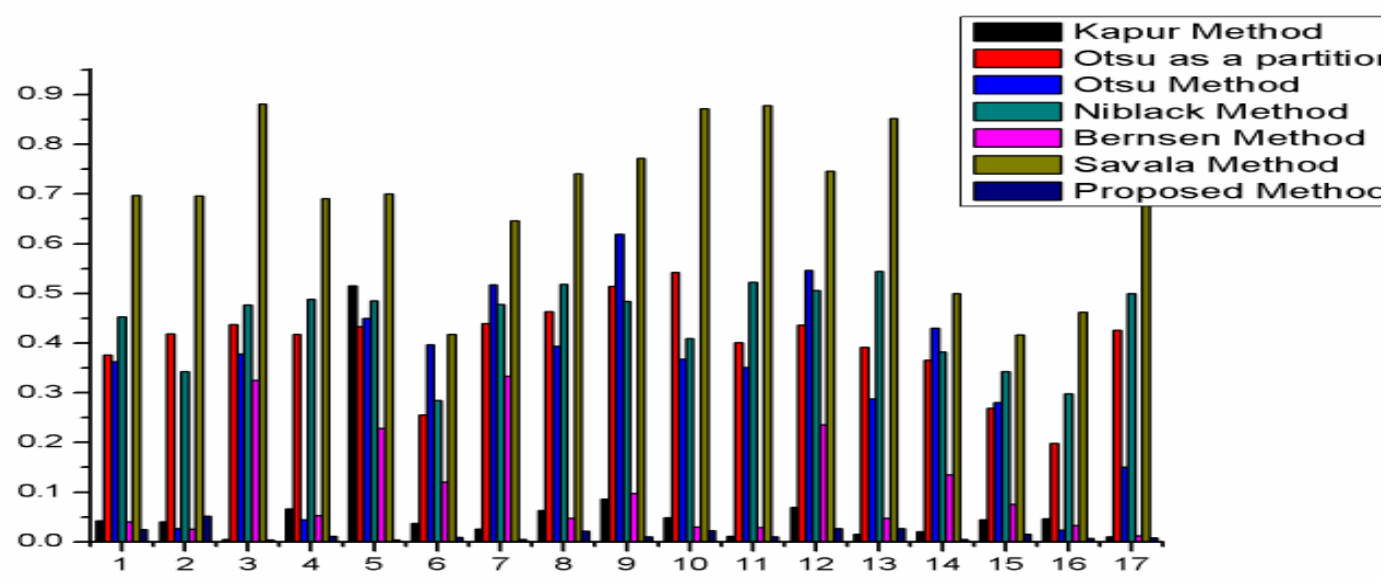

Figure 40: ME measurement graph

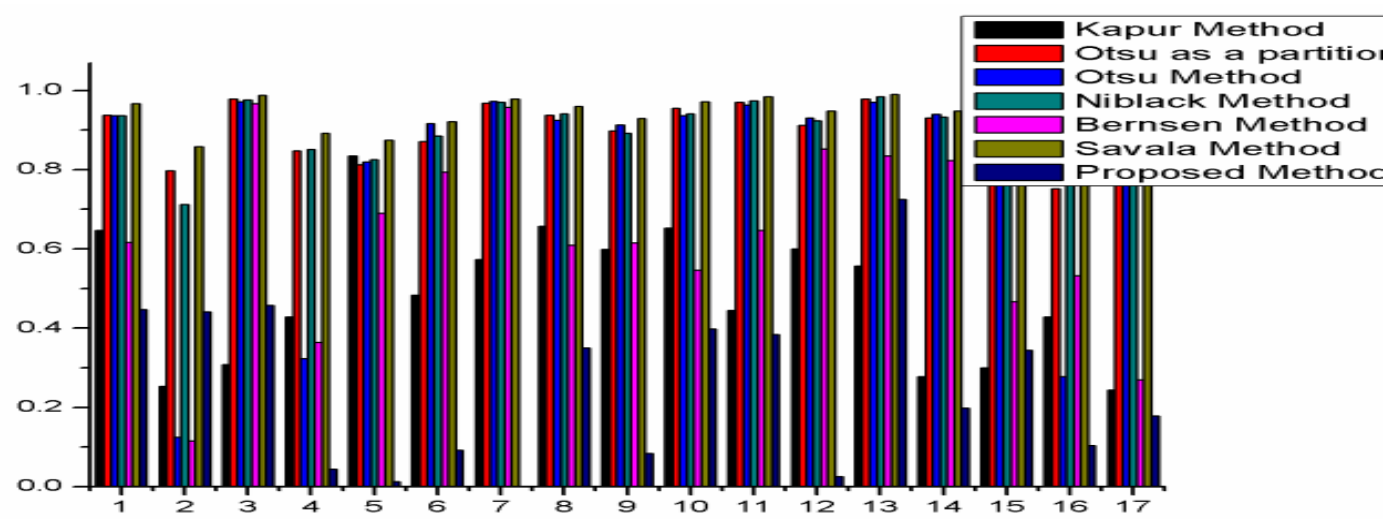

Figure 41: RAE measurement graph

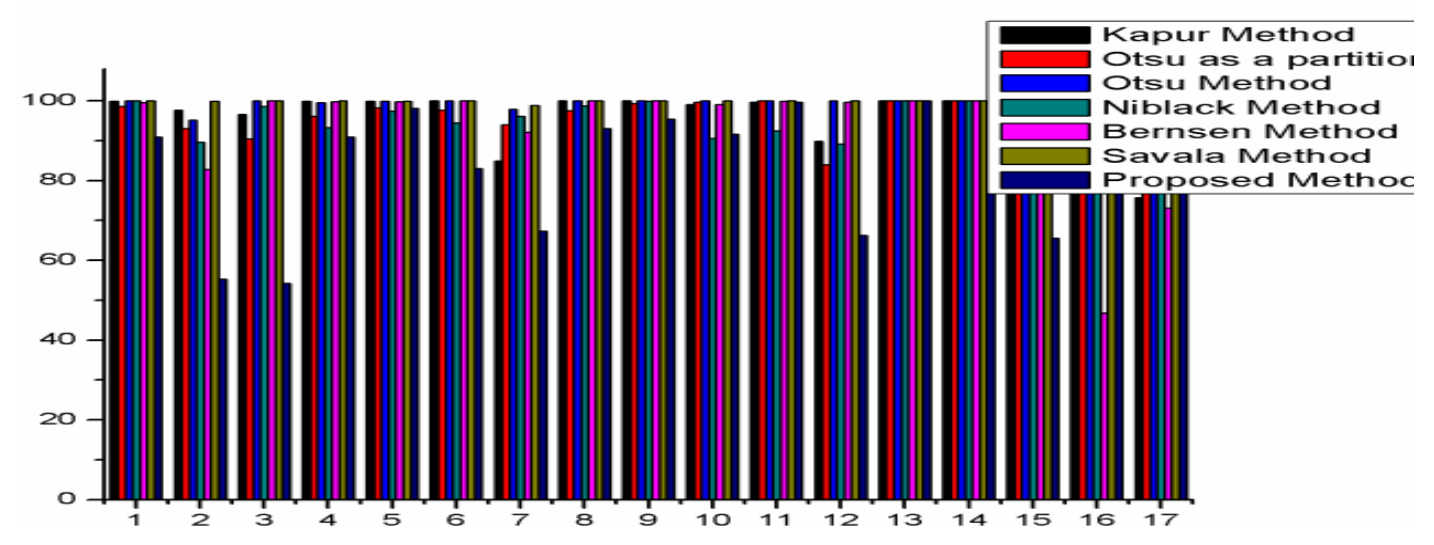

Figure 42: Recall measurement graph 


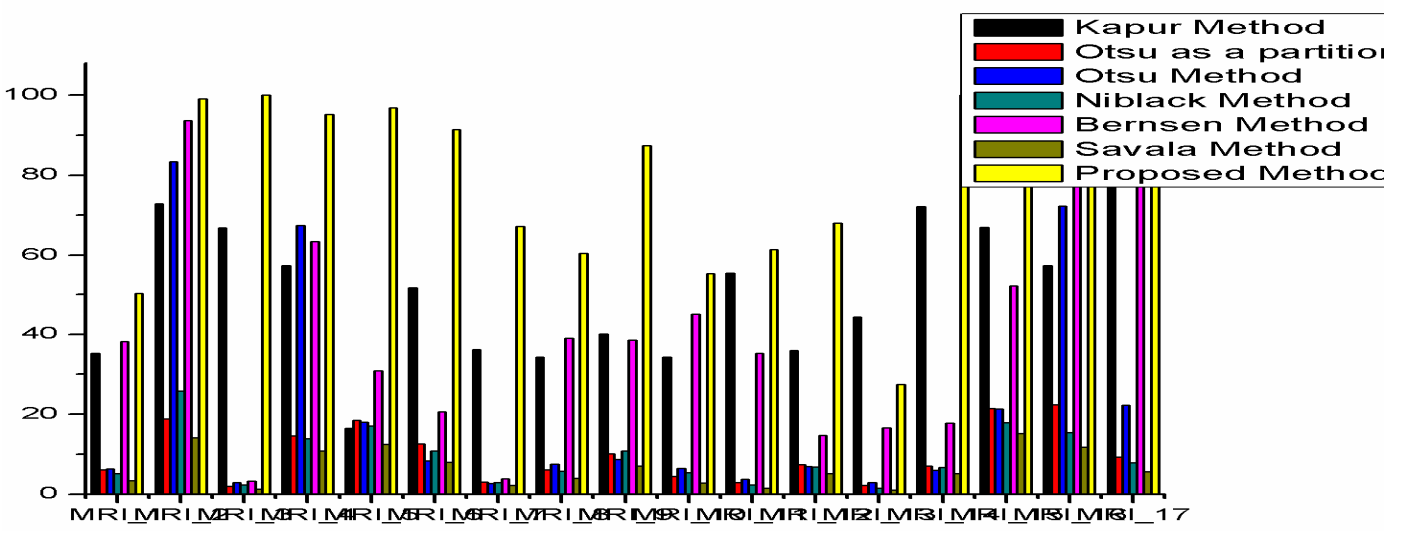

Figure 43: Recall measurement graph

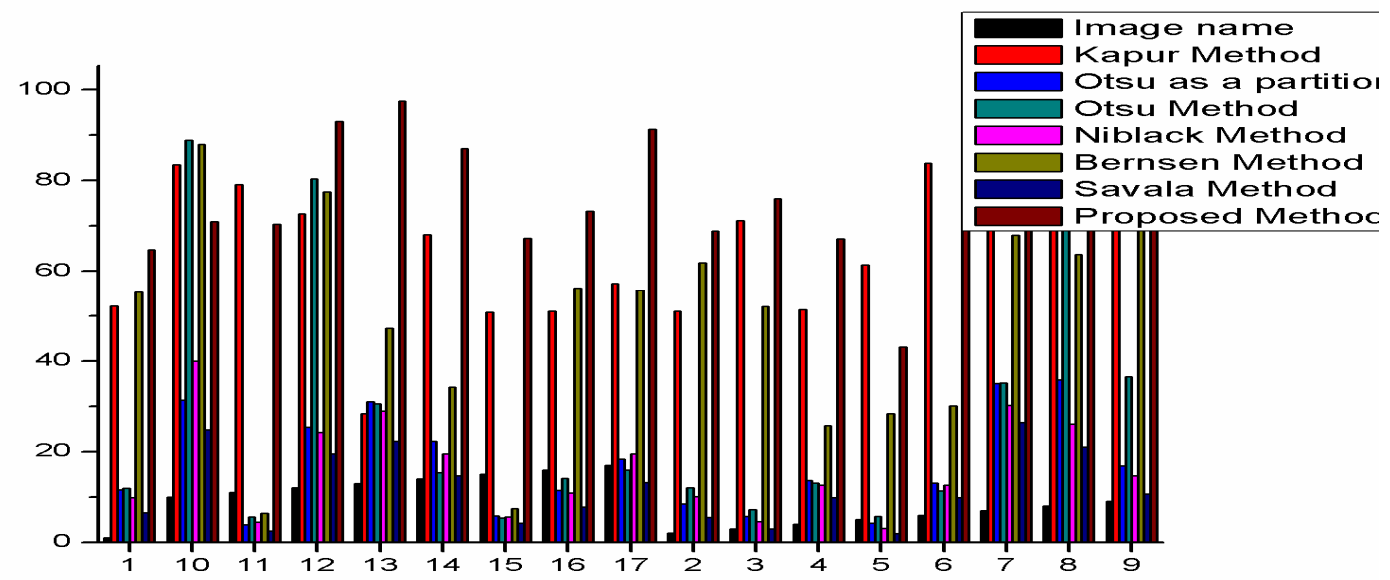

Figure 44: F measure measurement graph

\section{CONCLUSIONS AND FUTURE WORK:}

When different binarization method is being applied on MRI of brain data base the most of the algorithms binarized whole image without properly detecting the region of interest and the black background, so some method fails to give appropriate binarization. Thus the problem of variation of intensity level foreground to the background is totally overcome. Our proposed methods produce very good results for all type of MRI of brain images. We also proved that our proposed method produces better results visually as well as metric wise compare to the other established image binarization. Our method is very much simple it can be easily implement in any platform.

Here we create reference image manually because there is no suitable method of reference image creation for MRI of brain images thus in future we to develop a reference image creation methodology for MRI of Brain which will produce good reference image. 
Signal \& Image Processing : An International Journal (SIPIJ) Vol.3, No.6, December 2012

\section{REFERENCES}

[1] N. Otsu, "A Threshold Selection Method from Gray Level Histograms", IEEE Transactions on Systems, Man, and Cybernetics, SMC-9 (1979) 62-66.

[2] Sauvola, J., Pietikainen, M, “Adaptive document image binarization,” Pattern Recogn. 33(2), 225236 (2000).

[3] Niblack,W, “ An Introduction to Digital Image Processing,” pp. 115- 116. Prentice Hall, Eaglewood Cliffs (1986).

[4] Bernsen, J, “ Dynamic thresholding of gray level images," In: ICPR'86: Proceedings of the International Conference on Pattern Recognition, pp. 1251-1255 (1986).

[5] J. N. Kapur, P. K. Sahoo, A. K. C. Wong "A New Method for Gray-Level Picture Thresholding Using the Entropy of the Histogram” Computer Vision, Graphics, And Image Processing 29, 273-285 (1985).

[6] Soharab Hossain Shaikh ,Asis Kumar Maiti ,Nabendu Chaki," A new image binarization method using iterative partitioning" Springer- Machine Vision and Applications, 2012.

[7] Ntogas nikolaos. Ventzas dimitris, "A binarization algorithm for historical manuscripts", $12^{\text {th }}$ wseas international conference on communications, heraklion, greece, july 23-25, 2008.

[8] Mehmet Sezgin, Bulent Sankur, "Survey over image thresholding techniques and quantitative performance evaluation". Journal of Electronic Imaging 13(1), 146-165 (January 2004).

[9] R. C. Gonzalez, R. E. Woods. : Digital Image Processing. Second Edition, Prentice Hall, New Jersey, 2002.

[10] Stathis, P., Kavallieratou, E., Papamarkos, N.: "An evaluation technique for binarization algorithms." J. Univ. Comput. Sci. 14(18), 3011-3030, (2008).

[11] Gatos, B., Pratikakis, I., Perantonis, S.J.: Adaptive degraded document image binarization. Pattern Recogn. 39, 317-327 (2006)

[12] K. Sontasundaram and I'. Kalavathi, “ Medical Image Binarization Using Square Wave Representation” Spriliger-Vcrlag Berlin Heidelberg 2011.

[13] Y. Chen and G. Leedham, "Decompose algorithm for thresholding degraded historical document images," in IEE Proceeding Visual Image Signal Processing, December, 2005.

[14] Rodriguez, R.:Arobust algorithm for binarization of objects. Latin Am. Appl. Res. 40 (2010).

[15] Lopes, N.V., et al Automatic histogram threshold using fuzzy measures. IEEE Trans. Image Process. 19(1) (2010)

[16] Zhang, Y.J, “ A survey on evaluation methods for image segmentation” Pattern Recogn. 29, 13351346 (1996)

[17] Pan, M.S., Zhang, F., Ling, H.F, "An image binarization method based on HVS" ,m In: Proceedings of the 8th International Conference on Multimedia and Expo, pp. 1283-1286 (2007).

[18] Kuo, T.-Y., Lai,Y.Y., Lo,Y.-C., “A novel image binarization method using hybrid thresholding”, In: Proceedings of ICME, pp. 608-612 (2010).

[19] Sudipta Roy, Prof. Samir K. Bandyopadhyay "Detection and Quantification of Brain Tumor from MRI of Brain and it's Symmetric Analysis", International Journal of Information and Communication Technology Research(IJICTR), pp. 477-483, Volume 2, Number 6, June 2012.

[20] Sudipta Roy, Atanu Saha, Prof. Samir Kumar Bandyopadhyay. "Brain Tumor Segmentation And Quantification From Mri Of Brain”, Journal of Global Research in Computer Science(JGRCS), Volume 2, No. 4, April 2011 
Signal \& Image Processing : An International Journal (SIPIJ) Vol.3, No.6, December 2012

\section{Authors}

\section{Sudipta Roy}

He is pursuing M.Tech in the Dept. Of Computer Science \& Engineering, University of Calcutta, India. He received B.Sc (Phys Hons) from Burdwan University in the year 2008 and Post Graduate B.Tech from Calcutta University in the year 2011. He is Author of more than Ten publications in National and International Journal. Field of research interests are in the areas of image processing and staganography, more precisely biomadical image processing domain like MRI of brain , Breast cancer and Blood cells abnormalities detection, segmentation and quantification Data Structure, Artificial Intelligence, Programming Languages etc.

\section{Ayan Dey}

He is pursuing M.Tech in the Dept. Of Computer Science \& Engineering, University of Calcutta, India. He received B.Sc (Computer Sc. Hons) from Calcutta University in the year 2008 and PG B.Tech from Calcutta University in the year 2011. Field of interest is Image Processing, Moving Object Detection, Data Structure, Automata, Programming Languages etc.

\section{Kingshuk Chatterjee}

He received his M.Tech degree in Computer Science and Engineering from University of Calcutta in 2012. He received B.Sc(Phys Hons) from Calcutta University in the year 2007 and Post Graduate B.Tech from Calcutta University in the year 2010. His research interests includes DNA computing, Automata Theory, Medical image processing.

\section{Prof. Samir Kumar Bandyopadhyay}

B.E., M.Tech., Ph. D (Computer Science \& Engineering), C.Engg., D.Engg., FIE, FIETE, Sr. Member IEEE, currently, Professor of Computer Science \& Engineering, University of Calcutta, Kolkata, India. Visiting Faculty, Dept. of Comp. Sc., Southern Illinois University, USA, MIT, California Institute of Technology, etc. His research interests include Bio-medical Engg, Mobile Computing, Pattern Recognition, Graph Theory, Software Engg.,etc. He has 25 Years of experience at the Post-graduate and under-graduate Teaching \& Research experience in the University of Calcutta. He has already got several AcademicDistinctions in Degree level/Recognition/Awards from various prestigious Institutes and Organizations. He has published 300 Research papers in International \& Indian Journals and 5 leading text books for Computer Science and Engineering. Dr. Bandyopadhyay is the former Registrar of University of Calcutta and West Bengal University of Technology, Kolkata, and presently he is Vice Chancellor of West Bengal University of Technology, Kolkata, India.
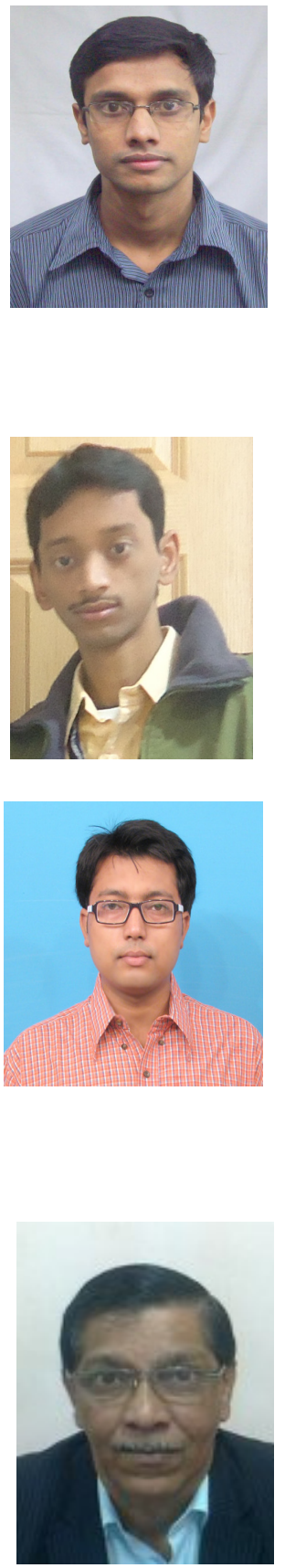